\title{
From Matter to Design: Empirical Experiments within a Design Context
}

\author{
ALEXANDER TIMMER \\ University of Wisconsin - Milwaukee
}

The intractable problems of architecture have remained not from a lack of attention but a lack of innovation in how architects explore, research, and reason within the bounds of those challenges. The lingering after-effects of this reality are reflected in, and potentially corrected through, the education of architects within the academy. Paramount to this reading of architectural pedagogy is the history of architecture as an object; the dominate historical mode of education within the academy. Opposed to that pedagogical practice is the emergent understanding of architecture as a system. This view of architecture invites a reevaluation of building and design through the lens of the isolated, closed, and open system. This filter then reorganizes the architectural canon into flat sculpture, form that is diametric to performance, and thermodynamically deep systems. These new categories break from the linear historical narrative of architecture, grouping buildings by their attitude towards their system boundary. This view of architecture demands opportunities for new methods of teaching and practicing within a design studio. In this essay, the empirical experiment will be posited as a prime methodological answer to this new epistemological regime. The empirical experiment, with its necessitated delimitation of a system boundary, offers the studio education a methodology for engaging the thermodynamically deep architecture: engaging form, matter, and performance as dialogue at various scales. Through an examination of a series of exercises from a design studio, the premise and execution of empirical experiment within a design context will be examined and articulated. Particular attention will be paid to the success and failures related to the translation of the empirical experiment to a spatial construction, as each shift in the system boundary of the project is imposed on the students.

\section{FROM MATTER TO DESIGN}

The intractable problems of architecture have remained not from a lack of attention but a lack of innovation in how architects explore, research, and reason within the bounds of those challenges. The lingering after-effects of this reality are reflected in, and potentially corrected through the education of architects within the academy. Paramount to this reading of architectural pedagogy is the history of architecture as an object; the traditional dominate mode of education within the academy. Opposed to that pedagogical practice is the emergent understanding of architecture as an open ecological system. This view of architecture invites a reevaluation of building and design through the lens of the isolated, closed, and open system. This filter then reorganizes the architectural canon into flat sculpture, form that is diametric to performance, and thermodynamically deep systems. These new categories break from the linear historical narrative of architecture, grouping buildings by their attitude towards their system boundary. This view of architecture demands opportunities for new methods of teaching and practicing within a design studio. In this essay, the empirical experiment will be posited as a prime methodological answer to this new epistemological regime. The empirical experiment, with its necessitated delimitation of a system boundary, offers the studio education a methodology for engaging the thermodynamically deep architecture, engaging form and performance as a dialogue at various scales.

The empirical experiment in architecture has a long history before the implementation of digital tools. The implementation of digital tools both doubled down on this methodology with the advent and development of digital fabrication, a practice that's primary impetus was the act of building, and at the same time pushed architecture away from physical testing, with the development of digital simulation tools. The evaluation of these architectures and their testing was not experienced in the final product. In the tradition of digital fabrication, early and integrated testing is hidden from view with the final project celebrated and evaluated on its closed, isolated terms. While construction techniques and methodologies are ever present in the digital fabrication regime, it lacks broader system implications at the scale of the region or environment.

Additionally, whether we think of Frank Lloyd Wright testing the columns at the Johnson Wax Building, Felix candela demonstrating the stability of his thin shell structures, or contemporary full-scale mockup constructed to work out the building details, each of these examples happened at the end of the design cycle. Each is intended to prove something after the act of design had taken place. The validity of the design process was paused, separated, and the architecture was tested as a fixed object. The experiment, the mockup, was still tied to the idea that the architect is producing a fixed and final object.

In this new regime of open systems, performance is understood not as a purely quantitative, as ASHRAE defines it, the "manner in which an individual, a building, a system, or a component fulfills specified behavior," but the act of formation. ${ }^{1}$ The act of formation is playing out within the studio as the 

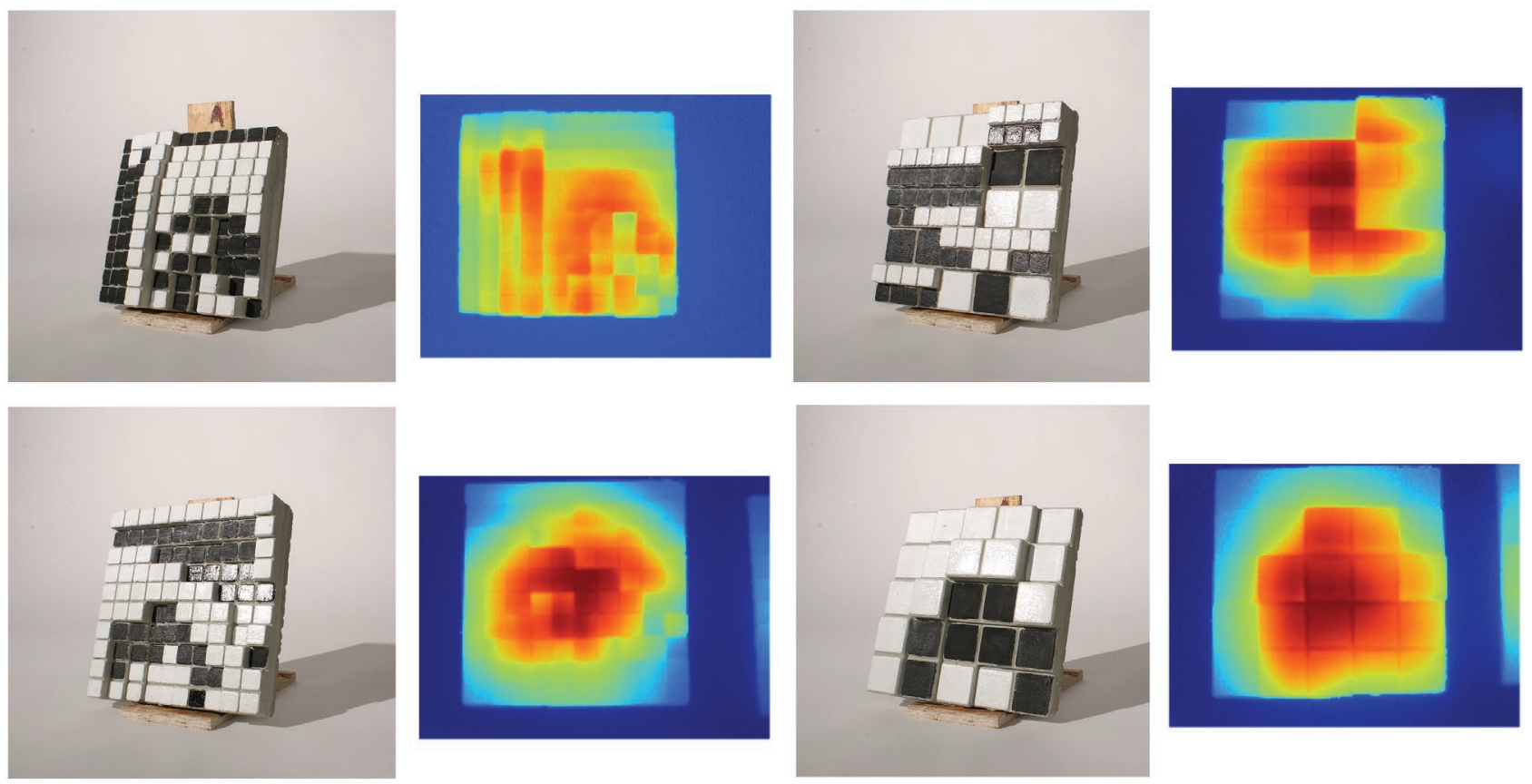

Figure 1. Generic material samples, concrete mixed with cotton fabric, Maddie Ninmann.

dialogue between matter and intent, and the connecting of feedback loops related to that dialogue. Performance in this view is closer to the definition of formation, and maybe closer yet to Darwin's definition of evolution. Darwin's argument for a "descent with modification" is extended to the whole of the design process, but rather than seeing the empirical experiment as a linear activity, early explorations can be reinterpreted through later exploration and vice versa. ${ }^{2}$ Rather than having each permutation, each performance of design, driven by the whim of an author, matter and its evaluation or evolution, strategically embedded within the design process encourage design and the object of design to be thought of as a system.

Architecture as an open system, the thermodynamically deep design, has in it certain contingent realities that offer opportunities for architects to engage the building as a series of flows that themselves exert a push and pull on the enactment of a design. A building or design can no longer be evaluated based on its form alone but must take into account the forces that act through it at the regional, building, and detail scale. Sourcing of material, questioning manufacturing techniques, engaging cultural interpretations and an understanding of political forces must invade the discourse of studio. This invasion will inevitably force us to rethink the structure of the studio and the ubiquitous design critique with its necessarily superficial responses to the broader issues of architecture considered as an open system. While this paper will argue for a redevelopment of the design process within the studio, through the empirical experiment, it will not delve too deeply in the whole of studio practice.

Through a reconsideration of the architectural design process as an open system, a system that passes both matter and energy beyond its designed system boundary, experimentation as design practice enters back into the conversation. By fundamentally changing the role of the model, from cold dead simulacrum to a living object with "needs," "desires," and "intentions" of its own, the architect is no longer reproducing known entities. Instead, through participation in an evolving process of "give and take" between their desires and intentions and the latent forces within the material of their design the architect develops a more powerful model. It should be noted that I do not intend to see the model through the lens of Object-Oriented-Ontology ala David Ruy, ${ }^{3}$ but to the materialism of Manual De Landa. ${ }^{4}$ We are not wishing into existing the ontological truth of architecture, but engaging its material reality through experiment. When we measure the surface temperature of a model, for example, we are merely engaging its physically inherent trait, there is no room in the engagement to entertain the new formalism of object orient ontology. 5,6

Empirical experiments can help to build mentalities and sensibilities about how to design within open systems. The empirical experiment, by its definition, demands an engagement with the subject matter that digital space hindered 

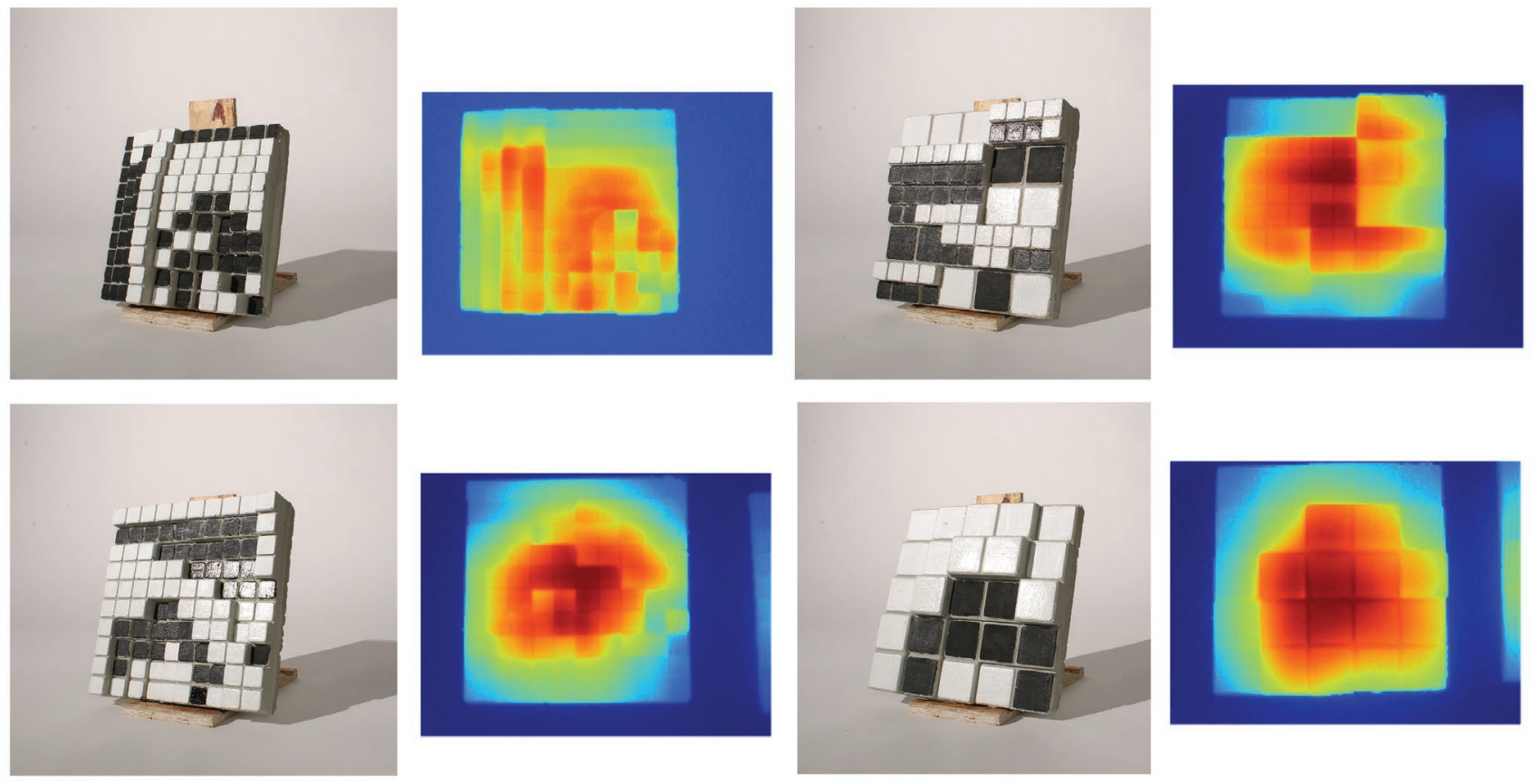

Figure 2. Specific material samples, Color and Surface Area, Andrew James Weiskopf.

through a detachment with technique, tool, and material. The empirical experiment necessitates engagement with these concerns and requires a clear delineation of system boundary. One of the primary epistemological and methodological concerns enumerated by Kiel Moe, that of the system boundary, cannot be ignored as the experiment requires a delimiting of that boundary and an acknowledgment of its limits as we scale up from the detail to space, to the building, and the region. ${ }^{7}$ Ideally as boundary layers are added, the architects recognize opportunities for the flow of matter and energy between scales under consideration.

The pedagogical prompt for these courses asked the students to consider the environmental concerns of our contemporary and future condition. As part of this dialogue, students recognized that while we are increasingly asked to design buildings that are ecologically robust and thermodynamically deep, the typically architectural response to this concern is the adherence to well-established standards and guidelines. ${ }^{8}$ As William W. Braham notes, LEED has increased the market penetration of environmentally focused practices, but it has done little to promote the fundamental change that is necessary. ${ }^{9}$ These courses seek to resist these traditional approaches and instead advance our ability to address environmental concerns as designers through a dialogue with material. ${ }^{10,11}$ The experiments of this studio, which will be examined in this essay, were designed to mandate a dialogue that welcomes material agency as an active and critical participant by beginning the design process.
The process for this pedagogical approach is structured as a series of material experiments, divided up by reflective exercises that asked the students to extrapolate from their experiments arguments about the relationship between form and performance. Each of those system boundary shifts is enumerated below. ${ }^{12}$ This essay will focus primarily on the studio Mass Matters that took place in the spring of 2018. This studio consisted of a series of material experiments, analysis of the data, representational exercises, and the design of a building. For this studio the system boundaries where the material, space, the building, and the environment. Successful projects took advantage of productive feedback loops between each of these boundaries.

\section{MASS MATTERS}

The studio Mass Matters specifically ask the students to consider the effects of mass in architecture from the standpoint of thermal comfort and building construction, given that its role in architecture to produce more durable buildings is made more polyvalent by the ability of that mass to thermally condition space. ${ }^{13}$ Any initial expenditure of energy to create a massive structure feeds back into the structure's ability to manage energy on a diurnal, seasonal, and generational timescale. For example, once a building has outlived its intended cultural use, it can be redesigned to provide a new thermal and programmatic regime. Thus, the relationship of matter and energy in architecture is a question of time and cycles. What we are often left with once a building has outlived its culturally determined use is a " 100 -year solution 

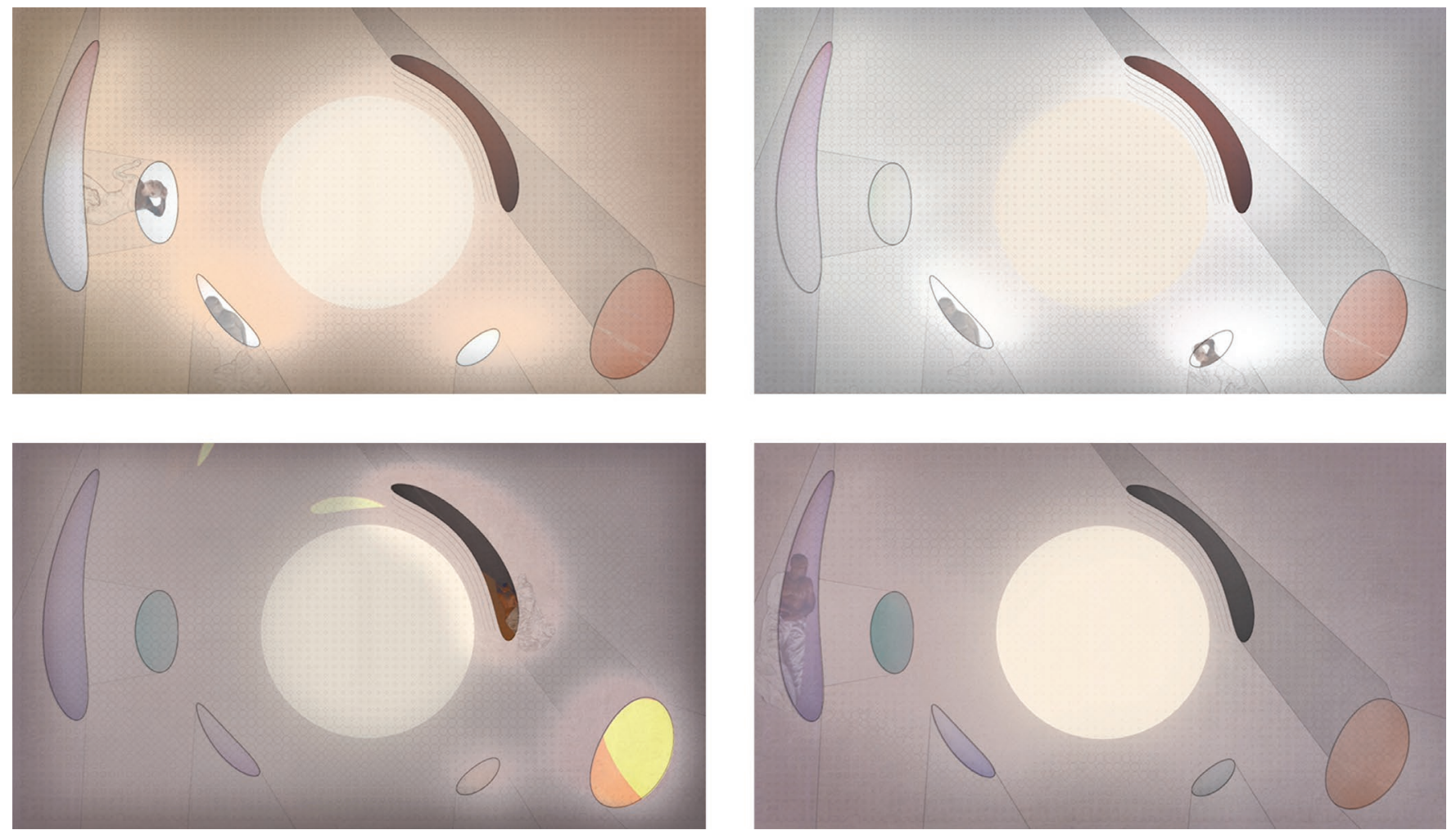

Figure 3. Frames from animation of space heating up and cooling down, Lucas Dedrick.

to a 20 -year problem. ${ }^{\prime 14}$ What is remaining then is the mass of the building. The same massive structure may be used by multiple generations in various ways as cultural and climatic requirements change. ${ }^{15}$

To do this, the studio looked at the adaptive reuse of the Marquette Ore Dock, located in the upper peninsula of Michigan. The ore dock is a large concrete structure, located in Lake Superior supported on submerged wooden piles. The structure itself was last used for its intended purpose in the 1970 s and has since laid dormant.

\section{SERIAL OR: MASTERING THE ART OF THE THERMALLY ACTIVE SURFACE}

The first of three exercises used iterative experiments to explore the various thermal qualities of materials the students designed. Concrete was the preferred medium for these experimentations as it allows the students to easily vary the density, volume, aggregate and surface quality of their samples. The studio was interested in exploring how these materials stored, transferred or resisted heat. This exercise sought to familiarize each student with a material process through iteration.

Each student was given an intensive or extensive material property to test. For example, a student given volume as their property produced four 12 " $\times 12$ " concrete samples of varying thickness, thus varying their overall volume. Another student was given surface area and proceed to mix fabric into their concrete sample (figure 1). Yet another student was given the material property of density, produced four 12 " $\mathrm{x}$ $12^{\prime \prime} \times .75^{\prime \prime}$ samples, varying the amount of water used in the mixture to produce several samples with different density. Other properties students explored where color, heat capacity, thermal conductivity, diffusivity, emissivity, absorbance, and surface area. Students were asked to consider how to modulate these properties appropriately and to document how each affects our thermal interaction with the material itself. These samples were referred to as the generic.

After producing the material samples, students used various techniques to heat the samples and document their thermal performance. When dealing with color, for example, the samples were brought out into the sun, and the relative rates of absorption were recorded with a thermal camera, spot infrared thermometer, and physically touching the samples themselves. Additionally, a convection oven was used to heat each sample for a fixed about of time evenly, 10 minutes, at a set temperature, 200 degrees Fahrenheit. Each sample was removed from the oven and let cool. Surface temperature measurements were taken every five minutes, and the various rates of cooling were compared across the samples.

The second of three exercises asked the students to synthesize their material properties with another student's material property. If one was assigned an intensive property, they 


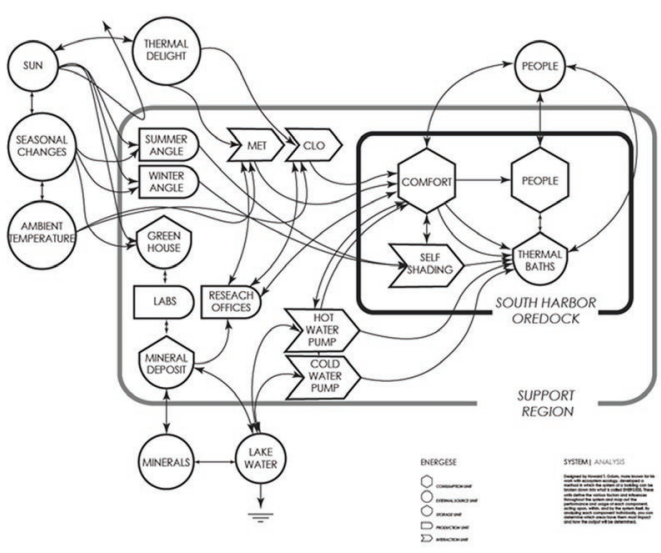

Figure 4. Thermal systems parti, Andrew James Weiskopf.

there asked to combine that property with an extensive one and vice versa. Each student produced an additional four 12 " x 12" samples that were again tested to explore their thermal properties (figure 2). An essential aspect of this step was to generate cross-pollination of ideas between students. Additionally, this made it apparent to each student how interdependent various material properties are. For example, a student exploring color in the first exercise would have a robust understanding of the effects of albedo on absorption and could test the rate of absorption by varying the density of four new samples, all painted black. These samples were referred to as the synthesized. All of the data was posted and shared amongst the studio.

\section{ENERGY OR: IN WHAT STYLE SHOULD WE DRAW?}

The third preliminary exercise asked the students to take their material samples, both the generic and the synthesized, and map them on to a generic space. Once mapped on the space students were asked to represent the thermal performance of their materials in space and time. The goal of this exercise and these animations was to encourage students to grapple with the representation of time, atmosphere, and the representation of otherwise invisible aspects of architecture. To jump-start these mappings, students were given one of Joseph and Annie Albers textiles or patterns to map onto space as a starting point. The colors of the textile or pattern were swapped out for the corresponding material sample that the student had designed.

After mapping the material to their generic space, the students were asked to bring the space to life, animating it with the thermal data, in most cases surface temperature, gathered from the previous exercises. This would be the first attempt to spatialize the atmospheric consequences of the previous material samples. Vital to this translation was the collected data, which itself demonstrated the performance of a material over time. This exercise also represents the first system boundary shift, going from the level of matter to space. Considerations had to be taken for orientation, sequence, organization, and proportion. Using GIFs and video animations student discovered various thermal and temporal juxtapositions within their collaged compositions (figure 3).

\section{PARTI PRIS OR: LEARNING FROM ODUM'S DIAGRAM}

To further break down the ingrained representation expectations of architecture, and before designing their building, the students were asked to develop a clear thermal parti further. Building off of Howard Odum's systems diagrams, "'students translated their first exercises into a drawing that could account for the various flows of matter and energy in their designs. As part of this exercise, the students took into account possible sources of energy with which to drive the phenomenon they had developed in the previous exercises. This parti had to take into account time, both in the performance of their materials and understanding of the seasonally changing environmental factors that would drive the project (figure 4). Additionally, Lake Superior the site for the studio was understood to be a reasonably consistent heat sink and source.

\section{MASS MATTERS OR: THE REDEVELOPMENT OF THE MARQUETTE ORE DOCK}

The students now had their toolkit. They had their designed material. A material that while familiar had been recontextualized as an active participant in the shaping of space. They had their spatial parti; A parti that took the form of an animated rendering of that space. They also had their thermodynamic parti, placing their material and spatial parti in the context of the various flows at the scale of its site. By building on each other and influencing each other, multiple feedbacks are developed between the different system boundaries. The system boundaries of material, space, building, and environment each feedback into the design in ways that layer on top of each other. The final figure of Jack Grover's final section demonstrates this series of connections. An early interest in modulating the density of concrete led to the embedding of pockets of air and water within the concrete. To do this the water and air were trapped within ping pong balls before casting them into the sample materials. Through the spatial exercise, the pockets of air and water were scaled up from the size of a ping pong ball to the scale of the human body, some penetrating the concrete and becoming furniture. With the system boundary shift to the environment, it was realized that the water from Lake Superior could be pumped through some of the water pockets maintaining a fixed temperature throughout the year while other pockets were allowed to 
change with the ambient temperature. This realization also led to the differentiation of the water pockets into two types and various sizes, seeking to address the varied thermal lag of water and air

\section{CONCLUSION}

In conclusion, the mandate of the physical experiment, that of the system boundary, requires architects to be aware of their assumed edge conditions. This awareness itself makes apparent the reality of architecture as an open system. The experiment, the empirical engagement with physical reality, necessitates an acknowledgment that buildings are built of matter which stores and transmit energy. This active role in a building's formation results in a more nuanced understanding of the building as an energy system itself. By engaging architecture from a matter first perspective, all other aspects of the built environment from programming to circulation to form and ornament can be reconsidered as part of the building energy system.

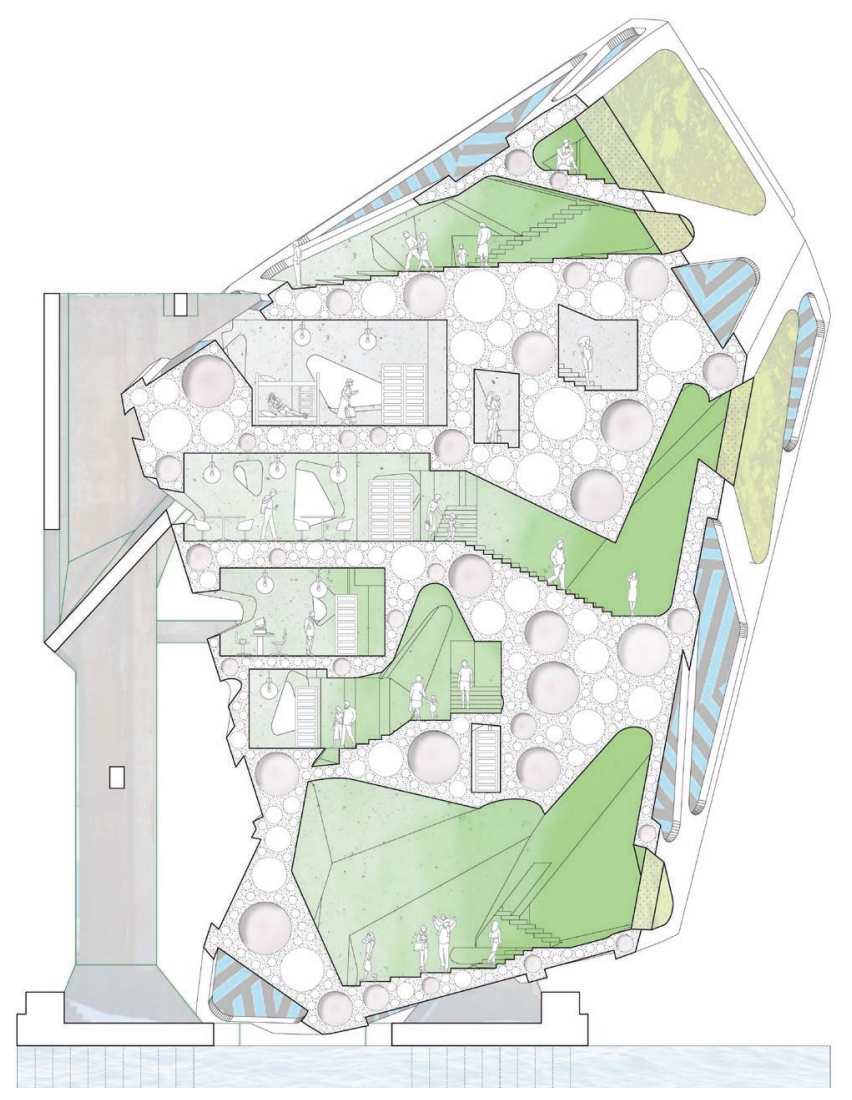

Figure 5. Section drawing by student, Jack Grover.

\section{ENDNOTES}

1 ASHRAE Glossary of Terms.

2 Charles Darwin, The Origin of Species (Boston: D. Appleton and Company, 1900).

3 David Ruy, "Returning to (Strange) Objects," TARP Architecture Manual: Not Nature (Spring 2012): 38-42.

4 Manuel Delanda, "Matter Matter," column in Domus Magazine, Issues 884 to 897.

5 Todd Gannon, Graham Harman, David Ruy, and Tom Wiscombe, "The Object Turn: A Conversation," Log 33 (2015): 73-94. http://www.jstor.org/ stable/43630852.

6 Mark Foster Gage, "Killing Simplicity: Object-Oriented Philosophy In Architecture," Log 33 (2015): 95-106. http://www.jstor.org/stable/43630853.

7 Kiel Moe, "Architectural Research in an Age of Open Systems,"Technology / Architecture + Design 2, no. 1 (2018): 8-10.

8 University of Wisconsin-Milwaukee (2018) ARCH 390 / 790: "Rough Cut: Mass, Material, Microclimate," course syllabus. Milwaukee, WI: Alexander Timmer.

9 William W. Braham, Architecture and Systems Ecology: Thermodynamic Principles of Environmental Building Design, in Three Parts (Abingdon, UK: Routledge, 2016).

10 University of Wisconsin - Milwaukee (2018) ARCH 650 / 850: "Matter Matters," course syllabus. Milwaukee, WI: Alexander Timmer.

11 University of Wisconsin - Milwaukee (2018) ARCH 390 / 790: Rough Cut: "Mass, Material, Microclimate," course syllabus. Milwaukee, WI: Alexander Timmer.

12 Alexander Timmer, "Abductive Architecture," a+t: Interior Matters 47 (May, 2017). For additional research on design reasoning within open systems and their relationship to system boundaries refer to this early text written by the author.

13 University of Wisconsin - Milwaukee (2018) ARCH 650 / 850: “Matter Matters," course syllabus. Milwaukee, WI: Alexander Timmer.

14 Stewart Brand, How Buildings Learn: What Happens After They're Built (London: Penguin Books, 2012).

15 University of Wisconsin - Milwaukee (2018) ARCH 650 / 850: “Matter Matters," course syllabus. Milwaukee, WI: Alexander Timmer. 